\title{
A telephone survey of parental attitudes and behaviours regarding teenage drinking
}

\author{
Bobby P Smyth*, Catherine D Darker ${ }^{\dagger}$, Erica Donnelly-Swift ${ }^{\dagger}$, Joe M Barry ${ }^{\dagger}$ and Shane PA Allwright ${ }^{\dagger}$
}

\begin{abstract}
Background: Irish teenagers demonstrate high rates of drunkenness and there has been a progressive fall in age of first drinking in recent decades. International research indicates that parents exert substantial influence over their teenager's drinking. We sought to determine the attitudes and behaviours of Irish parents towards drinking by their adolescent children.
\end{abstract}

Methods: We conducted a telephone survey of a representative sample of of 234 parents who had a teenager aged between 13 and 17 years.

Results: Six per cent reported that they would be unconcerned if their son or daughter was to binge drink once per month. On the issue of introducing children to alcohol in the home, $27 \%$ viewed this as a good idea while $63 \%$ disagreed with this practice. Eleven per cent of parents reported that they had given a drink to their teenager at home. Parents who drank regularly themselves, who were from higher socio-demographic groups and who lived in the east of Ireland demonstrated more permissive attitudes to teenage drinking.

Conclusions: We found no evidence of widespread permissive attitudes and behaviours among Irish parents. Given that parental influences have been demonstrated to exert substantial impact on teenage drinking, it may be possible to harness the concerns of Irish parents more effectively to reverse the trends of escalating alcohol related harm in Ireland.

\section{Background}

The third highest rate of drunkenness in Europe has been reported for Irish teenagers, with only teenagers from Britain and the Isle of Man getting drunk more frequently [1]. In the past two decades, the average age of onset of drinking has dropped dramatically in Ireland by 3.5 years to 15 years [2]. Mongan et al reported an increase in the number of children presenting to A\&E for alcohol related reasons in the past decade [3].

Early onset drinking is associated with a range of negative outcomes, including increased risk of later alcohol dependence [4-7], increased risk of drug abuse [8,9], criminal behaviour [10], sexual risk behaviour [11] and suicidal behaviour [12]. Recent research has also highlighted the negative impact which regular alcohol use can have on the developing adolescent brain [13].

\footnotetext{
* Correspondence: bobby.smyth@hse.ie

1 Department of Public Health \& Primary Care, Trinity College Dublin, Ireland + Contributed equally

Full list of author information is available at the end of the article
}

Although peers exert an important influence on teenage drinking $[14,15]$, research on familial risk and protective processes provides independent support for multiple domains of parental influence on adolescent drinking [15-17]. Parental alcohol use can influence adolescents' use, with greater parental alcohol use increasing the chance of early onset of alcohol use and subsequent unhealthy drinking patterns amongst adolescents $[15,17-$ 20]. There is good evidence that the establishment of clear alcohol specific rules leads to a delay in the onset of drinking [20-22]. Some researchers have cautioned that an extremely harsh authoritarian approach to teenage alcohol use may be counterproductive [23]. In Sweden, a brief prevention program which encouraged parents to maintain strict attitudes towards teenage drinking successfully reduced drunkenness [24]. A recent meta-analysis of parent and family preventions interventions demonstrated their effectiveness in reducing adolescent alcohol problems [25].

There appears to be wide diversity in parents' beliefs about how best to encourage non-harmful drinking 
behaviour in their children and considerable anxiety about what is the best approach [16,26,27]. Researchers also have quite polarised views on what parents should do $[18,28]$. In Britain, some parents have begun to embrace what they consider to be the 'continental model' and opt to introduce children to alcohol in the home at an early age. It has been advocated by Bellis et al, based on their finding that, among teenage drinkers, those who source alcohol from parents experience less alcohol related harm than those who source their alcohol elsewhere [28]. Almost half of the 15 and 16-year-olds in Bellis' study reported sourcing alcohol from parents. On the other hand, in a British qualitative study, it emerged that children brought up in families who embrace the 'continental model' tend to drink to excess while being extremely resistant to advice about alcohol related harms [26]. Warner \& White demonstrated that earlier introduction to drinking was associated with increased risk of later alcohol abuse, even if the introduction to alcohol occurred with parents [7]. In a qualitative Irish study of treatment attending teenagers with serious drug and alcohol problems, Palmer \& O'Reilly found that permissive attitudes of parents towards alcohol were linked to development of later problematic substance misuse [8]. In USA, Abar et al demonstrated that university students living away from home were more likely to drink excessively and to experience alcohol related harms if they grew up in a family which permitted underage drinking [18]. Others have also found that a permissive approach to teenage drinking is associated with greater alcohol abuse $[14,19]$. The vast majority of research on this issue has examined parenting practices based on the report of their children. A recent comprehensive review of underage drinking concluded that there was a need to gain a better understanding of parents' actual beliefs about this issue [15].

In light of the research evidence that indicates that parental attitudes and behaviours exert very significant influence on adolescent drinking, it is unlikely that the high rates of alcohol abuse demonstrated by Irish teenagers, the marked reduction in age of alcohol initiation and self-reported ease of access to alcohol are happening without the tacit consent of Irish parents. We sought to determine from parents themselves if the provision of alcohol to children is now widely supported and practised by parents in Ireland. We also sought to examine if parental attitudes and behaviours were associated with sociodemographic characteristics or associated with the parents' own drinking behaviours.

\section{Methods}

A telephone questionnaire survey was conducted to ascertain parental attitudes and behaviours regarding the introduction of their teenage children to alcohol in the home. The questionnaire was designed de novo. In addi- tion to questions on their socio-demographic characteristics, parents were asked if they had offered their teen a drink, what type of alcohol and on what types of occasions; about their attitudes to teen drinking; and their own drinking status.

A pilot survey on a convenience sample of 17 parents of teens (aged 13 -- 17 years) was carried out by members of the research team to assess the clarity and acceptability of the questions. Only minor wording changes were required. Five (29\%) of these parents said they had offered their teen a drink when they were having one. This proportion implies that a sample size of around 225 parents of teens would be required in order to estimate the proportion of Irish parents offering their teenage child an alcoholic drink within $\pm 6 \%$ with $95 \%$ confidence.

The survey was carried out by a commercial survey company, Ipsos MRBI. The Ipsos MRBI PhoneBus is a fortnightly telephone omnibus survey of the adult population of the Republic of Ireland aged $15+$ years which aims to collect a fully representative national sample of 1,000 adults (at least 950 adults $18+$ years in each wave) with census derived quota controls in terms of sex, age and region, and the Irish market research industry classification of social class (annual Joint National Readership Survey, based on census data and the quarterly national household survey estimates). Respondents were contacted for interview on both landline and mobile telephone numbers, using Random Digit Dialing. The sample includes $40 \%$ mobile phone numbers and $60 \%$ landline phone numbers. Minimum and maximum quota $(+/-$ $10 \%)$ are set and then data are weighted to yield the exact target. The survey was conducted in accordance with stipulations laid out by the Office of the Data Protection Commissioner. It also adhered to ESOMAR, MRS and AIMRO (of which Ipsos MRBI are members) requirements for conducting market research surveys.

The questions were administered only to respondents who had children. A random sample of 632 parents was contacted by telephone between September and November 2008, yielding 234 parents of teens (13-17 years). If the respondent had more than one child who was currently aged between 13-17 years, they were asked to answer the questions with respect to the child whose birthday came next. If they did not yet have any teenagers, they responded based on what they thought they might do or think in the future.

The term 'binge drinking' refers to an episode of excessive drinking. It is generally accepted that anything in excess of six 'units' or 'standard drinks' constitutes a binge. In order to explore parents' views about their teenager engaging in binge drinking, we asked them specifically about their views on their teenager drinking four pints of beer or the equivalent, this being 8 'units' or about 80 grams of pure alcohol on a single occasion. We 
also sought the views of parents of how many units they thought a person had to drink for the episode to be considered a 'binge'.

The Chair of Research Ethics Committee of the Faculties of Occupational Medicine and Public Health Medicine was contacted with regard to this study. The study was granted exemption.

\section{Statistical analysis}

Univariate analysis with the chi square test was conducted to determine predictors of Irish parents' attitudes towards teenage drinking. Odds ratios and their $95 \%$ confidence intervals were calculated.

We also determined an overall attitude score for each parent based upon their responses to the three attitude questions, namely views on provision of alcohol to their children by other adults, concern regarding binge drinking and views on the value of introducing children to alcohol in the home. For each question the response "strongly disagree" was assigned a score of zero, "slightly disagree" a score of 1 , "neither agree nor disagree" a score of 2, "slightly agree" scored 3 and responses of "strongly agree" scored 4. The cumulative score ranged from zero to twelve with low scores indicating conservative attitudes and high scores indicating permissive views on teenage drinking. As the data were highly skewed, we used the Mann Whittney $\mathrm{U}$ test to explore the parental characteristics associated with this overview score.

\section{Results}

\section{Descriptive characteristics, behaviours and attitudes}

All respondents were parents (i.e. none of the respondents were guardians). Overall, 632 parents had at least one child under 18 years of age in the household (339, $54 \%$ female and 293 , 46\% male). There were 234 parents with a teenager aged 13-17 years in the household. Table 1 provides descriptive statistics for parents with and without teenage children.

\section{Provision of alcohol to children by parents}

Only 25 (11\%) of parents of teens said they had offered their teen an alcoholic drink. The modal age at which this happened was 16 years $(n=10)$; four of these 25 parents gave their child a drink prior to their $15^{\text {th }}$ birthday. Most (19) of these parents provided the first alcoholic drink at a special occasion. Parents who provided drink to their teenagers usually provided beer (9) or wine (7).

Table 2 shows the parents' responses to the three attitude questions. Parents of teens were more likely to disagree with these three statements than parents of younger children.

Ninety per cent (211) of the parents of teenagers disagreed with the statement that it would be OK for another parent to give their teenager a drink. Parental response to this item was not associated with socio- demographic characteristics or with parental drinking frequency. Parents who had offered their son/daughter an alcoholic drink whilst they themselves were having a drink were significantly less likely to disagree with this statement than those who had not offered their teenager a drink (odds ratio [OR] 0.13, 95\% $\mathrm{CI}=0.04-0.39$ ) and parents of teenagers aged 17 years were significantly less likely to disagree than parents of teenagers aged 13 years (OR 0.07, 95\% C.I. $=0.01,0.62)$.

\section{Concern about binge drinking}

Two hundred and eleven parents of teens (90\%) disagreed with the statement "I would not be concerned if my son or daughter drank four pints of beer (or equivalent) once a month". No parental or teenager characteristic was significantly associated with response to this item.

\section{Introducing children to alcohol at home}

There was more divergence of opinion on the issue of introducing children to alcohol in the home with $27 \%$ of parents of teens agreeing that this was a good idea, $63 \%$ (148) disagreeing and 10\% being unsure. The characteristics of parents of teenagers who disagreed with this notion relative to parents who agreed that it was a good idea are presented in table 3 . Parents of teenagers who drank infrequently (OR 2.6) or not at all (OR 10), who were from the western and northern provinces of Connaught and Ulster (OR 4.0), or from lower socio-economic groups were significantly more likely to disagree with this idea. Parents who were working (OR 0.4) and those who said they had offered their teen a drink (OR 0.1 ) were significantly less likely to disagree (i.e. more likely to believe that it was a good idea to introduce children to alcohol in the home). There was a trend toward increased support for this idea among parents with more liberal definitions of binge drinking.

Table 4 presents a cumulative score indicating how permissive a parent was in terms of their attitudes to teenage drinking. Scores ranged from zero to 12, with a median of 1 and a mean of 1.9. Parents in the eastern province (Leinster, including Dublin) and parents from the two highest socio-economic groups (AB) were significantly more permissive (higher scores) than any of the other groups. Regular drinkers were significantly more permissive than infrequent or non-drinking parents and parents who had given alcohol to their children in the past were significantly more permissive than those who had not done so. The Cronbach alpha score for the reliability of this scale was 0.53 .

\section{Discussion}

This survey provides the first information on how parents in Ireland treat the issue of introducing alcohol to teens in the home. Among the parents with teenagers, just 11\% reported that they had given alcohol to their son or 


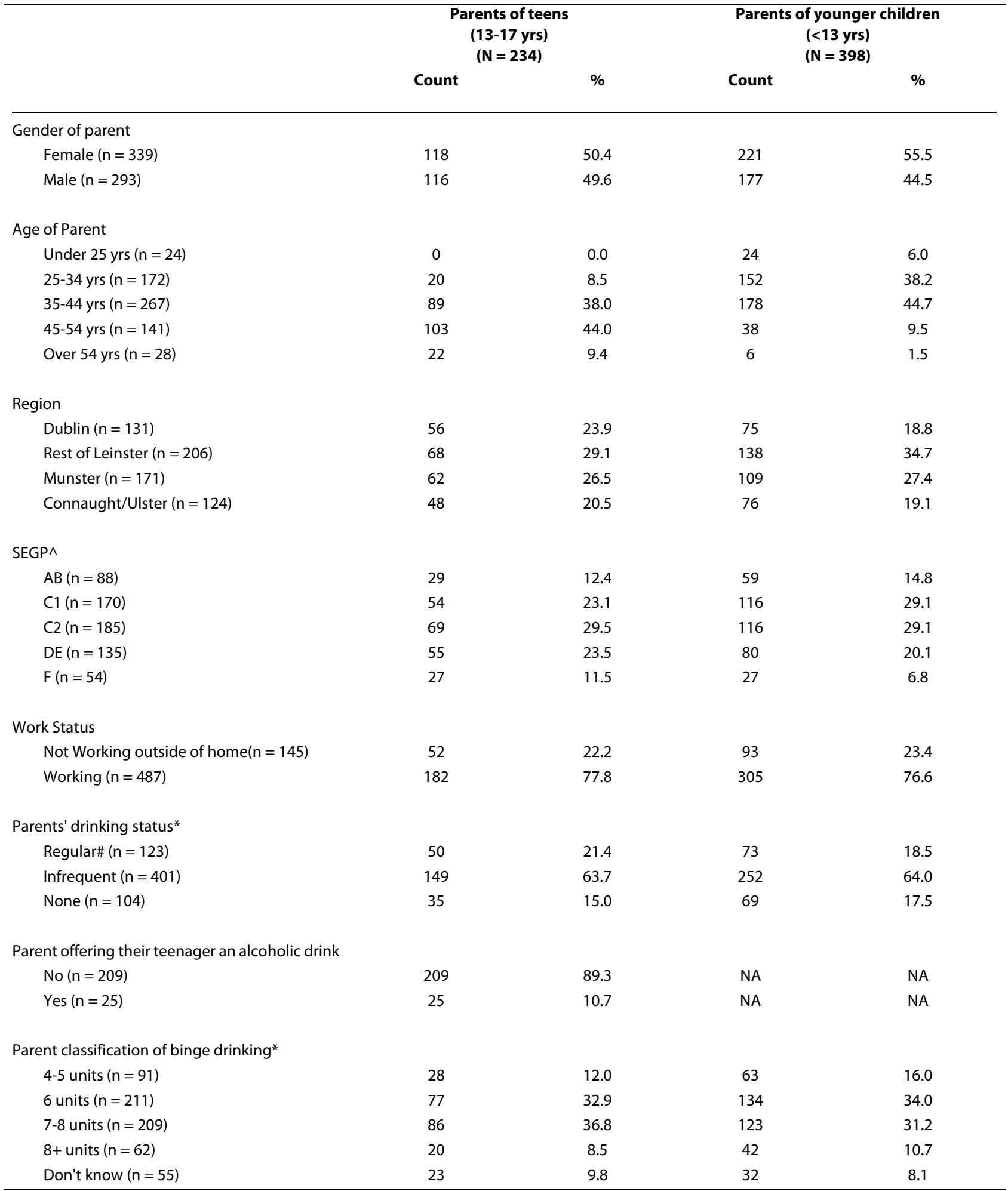

$\wedge$ SEGP classification: AB: upper \& middle class; C1: lower middle class; C2: skilled working class; DE: unskilled working class; F: farmers * There were four refusals/unknown responses.

\# Regular drinkers consumed alcohol at least twice per week. Infrequent drinkers consumed alcohol once per week or less frequently. 
Table 2: Attitudes of parent respondents towards teenage alcohol consumption $(n=628 *)$

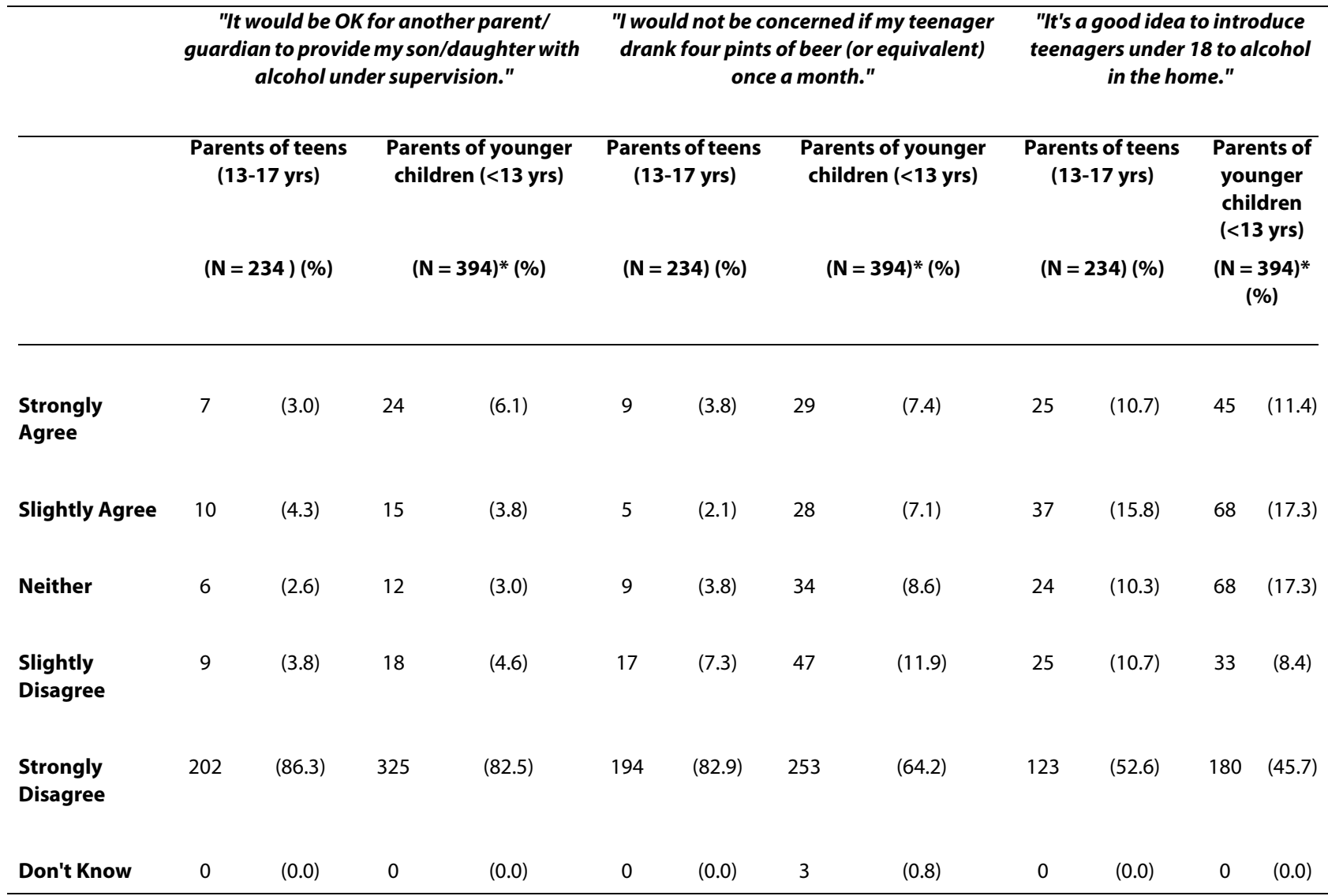

*There were four refusals/unknown responses.

daughter in the family context. Although Bellis et al examined a narrower age range and surveyed teenagers rather than parents, it appears that this behaviour is much more common in Britain [28]. Research from Sweden and New Zealand, has found that the vast majority of parents report a restrictive attitude towards supplying their teenagers with alcohol $[24,29]$. Where Irish parents provided alcohol, this occurred at age 16 or 17 in the majority of cases, and less than $2 \%$ of all parents had given their teenager alcohol before the age of 15 years. A similar pattern has also been found in Australia and New Zealand $[16,29]$. Our findings indicate that the progressive fall in age of first drinking in Ireland cannot be explained by widespread introduction of children to alcohol by parents. We know that drinking typically commences in Ireland now at age 14 or 15 years [2]. Hence, it is likely that many of the children who were 'introduced' by their parents to alcohol at home, were in fact already drinking for one or two years outside of home.

Just over a quarter of parents thought that it was a good idea to introduce their children to alcohol. This issue divided parents, with almost half strongly opposing this practice. A study in New Jersey by Warner \& White found that introduction to alcohol at a younger age, even if done at home, was predictive of later alcohol problems [7]. It is of concern that the parents who drank most regularly were more likely to embrace this idea and this mirrors findings from British research [26]. As in Britain, it appears that some Irish parents have attempted to introduce 'continental style' drinking to Irish homes in the hope that it will divert their teenage children away from 'binge' or heavy episodic drinking [26]. American research has highlighted the counterproductive impact of such approaches [18]. Where the pervasive culture is highly tolerant of heavy drinking, as it is in Britain and Ireland, early drinking is linked to later alcohol abuse $[8,22]$.

The vast majority of Irish parents would not permit another parent to give alcohol to their child. Also, around $90 \%$ of parents indicated that they would be concerned if their teenage son or daughter was binge drinking once a month, with only $6 \%$ being unconcerned by this behaviour. It is difficult to reconcile these findings with the very high rates of drunkenness and the frequent purchasing of alcohol reported by Irish teenagers $[1,8]$. This suggests that many Irish parents exert little control over their 
Table 3: Factors associated with parents of teenagers disagreeing with the statement that "It's a good idea to introduce teenagers under 18 to alcohol in the home"*

\begin{tabular}{|c|c|c|c|}
\hline & Odds Ratio & 95\% C.I. & P-value \\
\hline \multicolumn{4}{|l|}{ Gender of parent } \\
\hline Female & 1.0 & & \\
\hline Male & 0.9 & $(0.5,1.6)$ & NS \\
\hline \multicolumn{4}{|l|}{ Age of Parent } \\
\hline $25-34$ yrs & 0.9 & $(0.3,2.7)$ & NS \\
\hline $35-44$ yrs & 1.0 & & \\
\hline $45-54$ yrs & 0.7 & $(0.3,1.3)$ & NS \\
\hline Over 54 yrs & 0.7 & $(0.2,1.9)$ & NS \\
\hline \multicolumn{4}{|l|}{ Region } \\
\hline Dublin & 1.0 & & \\
\hline Rest of Leinster & 1.7 & $(0.7,3.7)$ & NS \\
\hline Munster & 1.8 & $(0.8,4.0)$ & NS \\
\hline Connaught/Ulster & 4.0 & $(1.5,10.8)$ & $<0.05$ \\
\hline \multicolumn{4}{|l|}{ SEGP^ } \\
\hline$A B$ & 1.0 & & \\
\hline $\mathrm{C} 1$ & 2.0 & $(0.7,5.4)$ & NS \\
\hline $\mathrm{C} 2$ & 2.7 & $(1.0,7.3)$ & $<0.05$ \\
\hline $\mathrm{DE}$ & 5.6 & $(1.8,7.0)$ & $<0.01$ \\
\hline $\mathrm{F}$ & 3.3 & $(0.9,11.2)$ & 0.06 \\
\hline
\end{tabular}

Work Status

Not Working outside of $\quad 1.0$

home

Working

Parents' drinking status\#

Regular
Infrequent

None

Parent had given their teenager an alcoholic drink

No
Yes

Parent classification of binge drinking

$4-5$ units
6 units
$7-8$ units

Table 3: Factors associated with parents of teenagers disagreeing with the statement that "It's a good idea to introduce teenagers under 18 to alcohol in the home"* (Continued)

\begin{tabular}{llll}
\hline $8+$ units & 0.5 & $(0.2,1.4)$ & NS \\
Don't know & 2.6 & $(0.7,9.9)$ & NS
\end{tabular}

Age of teenager

$\begin{array}{llll}13 \text { years } & 1.0 & & \\ 14 \text { years } & 0.6 & (0.2,1.5) & \text { NS } \\ 15 \text { years } & 0.4 & (0.2,1.1) & \text { NS } \\ 16 \text { years } & 0.6 & (0.2,1.6) & \text { NS } \\ 17 \text { years } & 0.4 & (0.4,1.2) & \text { NS }\end{array}$

* 148 parents who disagreed with the statement compared with 62 parents who agreed with the statement; 24 parents in the 'neither' category excluded.

$\wedge$ SEGP classification: AB: upper \& middle class; C1: lower middle class; C2: skilled working class; DE: unskilled working class; $F$ : farmers \# Regular drinkers consumed alcohol at least twice per week. Infrequent drinkers consumed alcohol once per week or less frequently.

teenage children's behaviour, or else they have been persuaded to accept regular drunkenness, despite their own concerns and unease about this behaviour. Research from Britain, Australia and Ireland supports this latter possibility with many parents reporting being confused about what to do and many feeling disempowered in addressing this issue $[16,26,27]$. International research indicates that parents consistently underestimate their children's drinking $[16,29]$.

In terms of socio-demographic trends, there was a tendency for parents from Dublin to have more liberal views than those in more rural locations and the lower socioeconomic group were the most conservative. In Britain it was also those from professional classes who were most inclined to provide alcohol to children at home [26]. In contrast, research from the Netherlands indicated that parents from higher socio-economic groups were stricter about alcohol [19]. They also found that being permissive about alcohol use was linked to greater alcohol abuse in teenagers, and that this effect was most pronounced in children from higher socio-economic groups. Our findings highlight challenges in terms of public policy formation, as those who exert most influence on policy in Ireland, including health professionals, politicians and journalists, belong to the permissive class on this issue [26].

The limitations of this study relate to the use of a nonvalidated questionnaire and that, although the sample is representative of the Irish population, it is modest in size. The reliability of the permissiveness score generated by combining responses to the three key issues explored was suboptimal, with a Cronbach alpha of 0.53 , which is lower 

attitudes.

\begin{tabular}{|c|c|c|c|c|c|}
\hline & number & mean & median & Inter Quartile Range & p value* \\
\hline Total group & 234 & 1.9 & 1 & $0-3$ & \\
\hline \multicolumn{6}{|l|}{ Gender of parent } \\
\hline Female & 116 & 1.9 & 1 & $0-3$ & \\
\hline Male & 118 & 1.9 & 1 & $0-3$ & NS \\
\hline \multicolumn{6}{|l|}{ Age of parent } \\
\hline Under 45 yrs & 109 & 1.7 & 1 & $0-3$ & \\
\hline 45 yrs and over & 125 & 2.1 & 1 & $0-4$ & NS \\
\hline \multicolumn{6}{|l|}{ Location } \\
\hline Dublin & 56 & 2.3 & 2 & $0-4$ & No sig diff between Dub, RoL \& Muns \\
\hline Rest of Leinster (RoL) & 68 & 2.3 & 1 & $0-3$ & \\
\hline Munster & 62 & 1.7 & 1 & $0-3$ & Con vs Dub, $<0.01$ Con vs RoL, 0.04 \\
\hline Connaught/Ulster & 48 & 1.3 & 0 & $0-2$ & Con vs Munster NS \\
\hline \multicolumn{6}{|l|}{ Socio-Economic Group } \\
\hline$A B$ & 29 & 2.7 & 3 & $1-4$ & \\
\hline $\mathrm{C}$ & 123 & 1.9 & 1 & $0-3$ & $A B$ vs $C, 0.03$ \\
\hline DE & 55 & 1.6 & 1 & $0-2$ & $A B$ vs $D E, 0.004$ \\
\hline $\mathrm{F}$ & 27 & 1.6 & 0 & $0-3$ & $A B$ vs $F, 0.02$ \\
\hline \multicolumn{6}{|l|}{ Parents drinking status\# } \\
\hline Regular & 50 & 2.8 & 2 & $0-4$ & \\
\hline Infrequent & 149 & 1.7 & 1 & $0-3$ & reg vs infreq 0.02 \\
\hline None & 35 & 1.4 & 0 & $0-2$ & non vs reg 0.003 infreq vs non, NS \\
\hline \multicolumn{6}{|c|}{$\begin{array}{l}\text { Parent had given their teenager an } \\
\text { alcoholic drink }\end{array}$} \\
\hline Yes & 25 & 4.5 & 4 & $3-6$ & \\
\hline No & 209 & 1.6 & 1 & $0-3$ & $<0.001$ \\
\hline
\end{tabular}

* Mann-Whitney U test

\# Regular drinkers consumed alcohol at least twice per week. Infrequent drinkers consumed alcohol once per week or less frequently.

than the rule of thumb reliability of 0.70 . This compromises its interpretation. However, it was designed to be as short as possible which necessarily compromised its reliability. The significant associations found between permissive attitudes and geographic region may possibly be explained by variations in work status and socio-economic group. Unlike most previous research on this topic, we focused on the views of parents, rather than on the teenagers' perceptions of their parents' attitudes.
Conducting a matched interview with their teenage sons and daughters and exploring their actual alcohol use and associated harms, would have added to the study, but was not practicable. Interviews were conducted via telephone and responses may have been different if face to face interviews had occurred. For example, telephone interviews have been shown to elicit higher levels of personal experience of alcohol related harms [30]. Although it is not illegal for parents to give alcohol to their children, it is 
a contentious topic and social desirability may have caused parents to under-report this behaviour [31].

\section{Conclusions}

Our findings do not lend support to a view that there is widespread complacency about teenage drinking among Irish parents. They are concerned and generally quite conservative about this issue. Hence, rather than being viewed as part of the problem, our findings suggest that parents represent a largely untapped resource and can be part of the solution in reversing the worrying trends of the past couple of decades.

\section{Competing interests}

The authors declare that they have no competing interests.

\section{Authors' contributions}

$\mathrm{BS}, \mathrm{SA}, \mathrm{CD}$ \& JB conceived the study and participated in its design. SA, CD, JB \& $B S$ designed the questionnaire and conducted the pilot study. SA coordinated the study. ED-S conducted the statistical analysis. BS took the lead on drafting the manuscript. All authors contributed to drafting of the manuscript and all have read and approved the final manuscript.

\section{Acknowledgements}

We are grateful to Prof Tom O'Dowd for his advice on the study concept and design and helpful comments on earlier drafts of the manuscript, and to Dr Alan Kelly for statistical advice. We are grateful to the Health Service Executive who funded the telephone survey.

\section{Author Details}

Department of Public Health \& Primary Care, Trinity College Dublin, Ireland

Received: 7 January 2010 Accepted: 1 June 2010

Published: 1 June 2010

\section{References}

1. Hibell B, Guttormsson U, Ahlstrom S, Balakireva O, Bjarnason T, Kokkevi A, Kraus L: The 2007 ESPAD Report: Substance use among students in 35 European countries. Stockholm, The Swedish Council for Information on Alcohol and Other Drugs; 2009.

2. O'Connor N, O'Connor M, Bradley CP: Alcohol -- How Much is Too Much? Ir Med J 2008, 101:200-202.

3. Mongan D, Reynolds S, Fanagan S, Long J: Health Related consequences of problem alcohol use. Overview 6. Dublin, Health Research Board; 2007.

4. Pitkanen T, Lyyra A, Pulkkinen L: Age of Onset of Drinking and the Use of Alcohol in Adulthood: A follow-up study from age eight to forty-two for females and males. Addiction 2005, 100:652-661.

5. Behrendt S, Wittchen H-U, Höfler M, Lieb R, Beesdo K: Transition from first substance use to substance use disorders in adolescence: Is early onset associated with a rapid escalation. Drug and Alc Depend 2009, 99:68-78.

6. DeWit DJ, Adlaf EM, Afford DR, Ogborne AC: Age at First Alcohol Use: A risk Factor for the development of Alcohol Disorders. Am J Psych 2000, 187:745-750.

7. Warner LA, White HR: Longitudinal effects of age at onset and first drinking situations on problem drinking. Subst Use Misuse 2003, 38:1983-2016

8. Palmer D, O'Reilly G: Young People, Alcohol and Drugs. Dublin, Juvenile Mental Health Matters; 2008

9. Kandel D, Yamoguchi K: From Beer to crack: Developmental patterns of drug involvement. Am J Pub Health 1993, 83:851-855.

10. Melzer-Lange MD: Violence and associated high-risk behavior in adolescents: Substance abuse, sexually transmitted diseases and pregnancy in adolescents. Ped Clin N Amer 1998, 45:307-17.

11. Steuve A, O'Donnell LN: Early alcohol initiation and subsequent sexual and alcohol risk behaviours among urban youths. Am J Public Health 2005, 95:887-893.
12. Swahn MH, Bossarte RM: Gender, Early Alcohol Use, and Suicide Ideation and Attempts: Findings from the 2005 Youth Risk Behavior Survey. J Adoles Health 2007, 41:175-181.

13. Monti PM, Miranda R, Nixon K, Sher KJ, Swartzwelder HS, Tapert SF, White A, Crews FT: Adolescence: Booze, brains and behaviour. Alcoholism:Clin Exper Res 2005, 29:207-220.

14. Wood MD, Read JP, Mitchell RE, Brand NH: Do parents still matter? Parent and peer influences on alcohol involvement among recent high school graduates. Psychol Addict Behav 2004, 18:19-30.

15. Zucker RA, Donovan JE, Masten AS, Mattson ME, Moss HB: Early developmental processes and the continuity of risk for underage drinking and problem drinking. Pediatrics 2008, 121:S252-s272.

16. Hayes L, Smart D, Toumbourou JW, Sanson A: Parental influences on adolescent alcohol use. Melbourne, Australian Institute of Family Studies; 2004

17. Newbury-Birch D, Walker J, Avery L, Beyer F, Brown N, Jackson K, Lock CA McGovern R, Kaner E, Gilvarry E, McArdle P, Ramesh V, Stewart S: Impact of alcohol consumption on young people: a systematic review of published reviews. London, Department for Children, Schools and Families; 2009 .

18. Abar C, Abar B, Turrisi R: The impact of parental modeling and permissibility on alcohol use and experienced negative drinking consequences in college. Addict Behav 2009, 34:542-7.

19. Spijkerman R, van der Eijnden RJJM, Huiberts A: Sociodemographic differences in alcohol-specific parenting practices and adolescent drinking patterns. Eur Addict Res 2008, 14:26-37.

20. van der Vorst $H$, Engels RCME, Meeus W, Dekovic M: The impact of alcohol-specific rules, parental norms about early drinking and parental alcohol use on adolescents' drinking behavior. J Child Psychol Psych 2006, 47:1299-1306

21. Kosterman R, Hawkins JD, Guo J, Catalano RF, Abbott RD: The dynamics of alcohol and marijuana initiation: Patterns and predictors of first use. Am J Public Health 2000, 90:360-366.

22. Blobaum EM, Anderson JF: The impact of exposure and perceived disapproval of underage drinking. Crim Just Stud 2006, 19:171-192.

23. Foxcroft $D R$, Lowe G: Adolescent drinking behaviour and family socialization factors: A meta-analysis. J Adolesc 1991, 14:255-73.

24. Koutakis N, Stattin H, Kerr M: Reducing youth alcohol drinking through a parent-targeted intervention: the Orebro Prevention Program. Addiction 2008, 103:1629-1637.

25. Smit E, Verdurmen J, Monshouwer K, Smit F: Family interventions and their effect on adolescent alcohol use in general populations; a metaanalysis of randomized controlled trials. Drug Alc Depend 2008, 97:195-206.

26. Department of Children, Schools \& Families: Use of alcohol among children and young people. London; 2008.

27. van Hout MCA: Youth alcohol and drug use in rural Ireland -- parents' views. Rural Remote Health 2009, 9:1171

28. Bellis MA, Phillips-Howard PA, Hughes K, Hughes S, Cook PA, Morleo M, Hannon K, Smallthwaite L, Jones L: Teenage drinking, alcohol availability and pricing: a cross-sectional study of risk and protective factors for alcohol-related harms in school children. BMC Public Health 2009, 9:380.

29. Kypri K, Dean JI, Stojanovski E: Parents attitudes on the supply of alcohol to minors. Drug Alc Review 2007, 26:41-47.

30. Midanik LT, Greenfield TK, Rogers JD: Reports of alcohol-related harm: Telephone versus face-to-face interviews. J Stud A/c 2001, 62:74-78.

31. Holbrook AL, Green MC, Krosnick JA: Telephone versus face-to-face interviewing of national probability samples with long questionnaires: Comparisons of respondent satisficing and social desirability response bias. Public Opinion Quart 2003, 67:79-125.

Pre-publication history

The pre-publication history for this paper can be accessed here: http://www biomedcentral com/1471-2458/10/297/prepub

doi: 10.1186/1471-2458-10-297

Cite this article as: Smyth et al., A telephone survey of parental attitudes and behaviours regarding teenage drinking BMC Public Health 2010, 10:297 